\title{
An HIV-1 Positive Woman Without Usual Immunodeficiency
}

\author{
Bagher Moradi (iD ${ }^{1, *}$ and Saeed Keshvari ${ }^{2}$ \\ ${ }^{1}$ Department of Basic Sciences, Esfarayen Faculty of Medical Sciences, Esfarayen, Iran \\ ${ }^{2}$ Department of Health Sciences, Esfarayen Faculty of Medical Sciences, Esfarayen, Iran \\ "Corresponding author: Department of Basic Sciences, Esfarayen Faculty of Medical Sciences, Esfarayen, Iran. Email: moradib901@gmail.com
}

Received 2021 August 25; Revised 2021 November 09; Accepted 2021 November 14.

\begin{abstract}
Introduction: Acquired immune deficiency syndrome (AIDS) inflicts severe damage to the immune system. It is transmitted from one person to another through blood transfusion and vertical and sexual transmission. It should be noted that almost all papers reporting AIDS emphasized that HIV led to immune deficiency. However, this study reported the first HIV-1 seropositive woman who had an active viral load of HIV-1 without any signs or CD4 lymphocyte count depletion.

Case Presentation: This study reported a 46-year-old HIV-1 seropositive woman without any signs and symptoms diagnosed 31 years ago by laboratory tests. Also, it is noteworthy that the patient had not received regular therapeutics during the infection period. Our serologic tests showed an active seropositive patient without any CD4 depletion. The viral load of HIV-1 was $132967.2 \mathrm{u} / \mathrm{L}$, which was quantified by a real-time PCR assay. Also, a CBC test was performed and showed no abnormal results.

Conclusions: An untreated HIV-1 positive patient without immunodeficiency is a rare condition, and we found no report of it in the literature. This article reported an HIV-1 positive patient in whom the infection was confirmed several times using the real-time PCR method.
\end{abstract}

Keywords: HIV-1, Infection, Lymphocyte, Women, Therapeutics

\section{Introduction}

Acquired immune deficiency syndrome (AIDS) is a progressive and preventable disease caused by replicating the human immunodeficiency virus (HIV) in the patient's body. After transmission to the host body, HIV penetrates the mucosal tissues and spreads to the lymphatic organs after a few days. HIV primarily targets CD4 $+\mathrm{T}$ cells (1). Around day 10, the virus can be detected in the blood, and around day 30, when HIV reaches its peak, the antibody level becomes detectable. The disease then enters the immune phase, where the level of HIV proliferation often remains relatively constant for years (2). HIV gradually destroys T CD4 + cells, and HIV triggers serious damage to the immune system $(3,4)$. After several years, a profound immunodeficiency appears, and people develop multiple infectious or malignant complications. AIDS usually progresses to death over a period of about ten years; however, this occurs more rapidly in some patients and more slowly in some others (5). HIV can be transferred from one person to another by blood transfusions and vertical and sexual transmission. In general, major symptoms appear in the patient several years after immunodeficiency (6). It is needed to mention that AIDS can be more important in women, especially pregnant women, because, like some in- fectious diseases, it can affect the fetus and newborns (7). The signs are usually the outcome of a compromised immune system and enable the diagnosis of AIDS by laboratory diagnosis using serology and CD4 assay. To confirm AIDS, real-time PCR should be done in which active viral load can be measured $(8,9)$. HIV-1 positive people usually show signs after developing a deficiency in their immune system (4). According to clinical presentation and laboratory examination, AIDS has been divided into two categories: asymptomatic and symptomatic (10). There are no clear clinical symptoms during the asymptomatic phase in which the immune system can be affected and initially compromised. Also, patients in the early phase of the disease have no immunodeficiency or CD4 depletion over the first ten years (11). It should be noted that almost all papers reporting the late phase of AIDS emphasized that HIV resulted in immune deficiency, and there is no report indicating active infection without immunodeficiency. This study reported a 46-year-old HIV-1 seropositive woman with an active viral load of HIV-1 but without any sign or CD4 depletion 30 years after the initial diagnosis. It is necessary to mention that the patient had not received any medication during this long period. 


\section{Case Presentation}

The patient was a 46-year-old woman without clinical presentations such as rash, OPC, neurologic symptoms, and lymphadenopathy; however, the patient's left eye was blind. When she was checked up before her pregnancy 31 years ago, laboratory tests detected her as an HIV-1 seropositive patient. The patient was checked every year without any changes in the results and avoided treatment after ATR prescription by a physician. Given the absence of any reported signs in the patient, we decided to study other laboratory tests such as hematology and molecular examinations. The CBC results showed WBC, RBC, HGB, HCT, PLT values as 5400, 4840000, 14, 48.8, 197000, respectively. The latest CD4 examination showed $610 \mathrm{u} / \mathrm{L}$, and the HIV-1 realtime PCR assay measured viral load as 132967.2.

Doctors encouraged the patient to take drugs because of persistently positive serology and viral load results, but she was reluctant to do so. The patient was periodically examined by health staff and had normal daily life after 31 years.

\section{Discussion}

The present study reported a rare HIV-1 positive woman without immunodeficiency who avoided taking medications over the infection period. According to our search in the literature, we found that she was the first HIV-1 positive case without immunodeficiency. Several studies have reported patients with various clinical presentations $(12,13)$. HIV-1 positive people usually show symptoms after the development of immunodeficiency (4). According to the clinical presentation and laboratory examination, AIDS has been divided into two categories: asymptomatic and symptomatic (10). In Willard's study, a survey of clinical reports showed no clear clinical symptoms during the asymptomatic phase and that patients in the early phase of disease were those without immunodeficiency or CD4 depletion at the first ten years of AIDS (11). However, the analysis of the genetic association with virus binding to host cells in several large AIDS cohort studies has shown 14 disease-limiting genes or AIDS restriction genes (ARG) that control HIV-1 entry into host cells, acquired and innate immunity, and cytokine responses (14). For example, in Dean et al.'s study, it was shown that the CCR5 gene and $\Delta 32$ alleles could prevent the onset of AIDS infection (15). Also, it was cleared in another study that the translational effect of ARG on the individuals' susceptibility to AIDS was significant (14). Thus, in some patients, we may see slow progressors according to their genetic properties. Now we can propose that our case can have some ARGs that prevent or slow down HIV-1 infection. Furthermore, cytokine gene variation is important in HIV positive patients without signs. For example, in Shin et al.'s study, IL10, 5'A allele could decrease IL10 expression and limit HIV infection (16). Nevertheless, during latent AIDS, patients' immune system is affected by HIV replication, and CD4 depletion causes immunodeficiency and the development of various clinical signs. In Hooshmand's research, it was revealed that most patients with AIDS developed symptomatic AIDS during the first decade if not taking ATR and that they would probably die within two years. After antiviral therapy, the patient may live for more than ten years and even have a normal life expectancy (17). In contrast with the result of this study, our report revealed that AIDS could be asymptomatic even after many years without any treatment. However, in Carrington's study, it was determined that HLA variation gene and $\mathrm{B}^{*} 27$ allele function in some patients could delay HIV infection (18), confirming our HIV-positive patient position. Laboratory tests are standard markers for the evaluation of a patient's immunodeficiency. In most patients and after one decade and in the latent phase, viral replication can damage cellular immunity, and in particular, CD4 cells decrease to less than 500 $\mathrm{u} / \mathrm{L}$. According to the study of Sousa et al., if CD4 counts decrease and reach $>200 \mathrm{u} / \mathrm{L}$, immunodeficiency can be confirmed in the patient (19). Unlike the mentioned study, we found that the seropositive patient with a specific viral load did not have immunodeficiency or symptoms.

Siegel et al. reported that the manifestation of disease symptoms and severity affected the course of treatment. The reason is that if patients do not have a specific symptom, they may refuse to visit a doctor and follow a medication regimen. On the other hand, if they have severe symptoms, they may experience poor quality of life regarding physical and mental aspects (20). According to this report, the lack of symptoms in an HIV-positive patient may justify the reluctance to receive drugs.

Serologic tests, real-time PCR, and CD4 assay are essential in diagnosing viral infections such as HIV. However, we seldom visit an HIV-1 seropositive patient with an active viral load but without CD4 depletion in the third decade after infection.

\section{Footnotes}

Authors' Contribution: B.M: Conceptualization and design, writing of the original draft, sample collection; S.K: Conceptualization and design

Conflict of Interests: The authors have conflicts of interest to disclose.

Ethical Approval: The Research and Ethics Committee of the Esfarayen University of Medical Sciences 


\section{(IR.ESFARAYENUMS.REC.1400.001).}

Funding/Support: This study was supported by a grant from the Esfarayen University of Medical Sciences.

Informed Consent: Written informed consent was obtained from the patient.

\section{References}

1. Akan S, Ediz C, Kizilkan YE, Alcin A, Tavukcu HH, Yilmaz O. COVID-19 infection threat in patients with high-risk non-muscle invasive bladder cancer receiving intravesical BCG therapy. Int J Clin Pract. 2021;75(3). e13752. doi: 10.1111/ijcp.13752. [PubMed: 33064918]. [PubMed Central: PMC7646056].

2. Mellors JW, Rinaldo CJ, Gupta P, White RM, Todd JA, Kingsley LA. Prognosis in HIV-1 infection predicted by the quantity of virus in plasma. Science. 1996;272(5265):1167-70. doi: 10.1126/science.272.5265.1167. [PubMed: 8638160].

3. McCune JM. The dynamics of CD4+ T-cell depletion in HIV disease. Nature.2001;410(6831):974-9. doi:10.1038/35073648. [PubMed:11309627].

4. Moir S, Chun TW, Fauci AS. Pathogenic mechanisms of HIV disease. Annu Rev Pathol. 2011;6:223-48. doi: 10.1146/annurev-pathol-011110130254. [PubMed: 21034222].

5. Deeks SG, Walker BD. Human immunodeficiency virus controllers: mechanisms of durable virus control in the absence of antiretroviral therapy. Immunity. 2007;27(3):406-16. doi: 10.1016/j.immuni.2007.08.010. [PubMed: 17892849].

6. Shaw GM, Hunter E. HIV transmission. Cold Spring Harb Perspect Med.2012;2(11). doi:10.1101/cshperspect.a006965. [PubMed: 23043157]. [PubMed Central: PMC3543106].

7. Moradi B, Meshkat Z. [Evaluation of tuberculosis infection in pregnant women and its effects on newborns: an Overview]. Iran J Obstet Gynecol Infertil. 2015;18(178):21-36. Persian. doi: 10.22038/ijogi.2016.6498.

8. Bradley H, Hall HI, Wolitski RJ, Van Handel MM, Stone AE, LaFlam M, et al. Vital signs: HIV diagnosis, care, and treatment among persons living with HIV-United States, 2011. MMWR. 2014;63(47):1113.

9. Iweala OI. HIV diagnostic tests: an overview. Contraception. 2004;70(2):141-7. doi: 10.1016/j.contraception.2004.03.012. [PubMed: 15288219].
10. Centers for Disease Control. Classification system for human Tlymphotropic virus type III/lymphadenopathy-associated virus infections. MMWR. 1986;35(20):334-9.

11. Willard S, Holzemer WL, Wantland DJ, Cuca YP, Kirksey KM, Portillo CJ, et al. Does "asymptomatic" mean without symptoms for those living with HIV infection? AIDS Care. 2009;21(3):322-8. doi: 10.1080/09540120802183511. [PubMed: 19280409]. [PubMed Central: PMC3630501].

12. Singer EJ, Valdes-Sueiras M, Commins D, Levine A. Neurologic presentations of AIDS. Neurol Clin. 2010;28(1):253-75. doi: 10.1016/j.ncl.2009.09.018. [PubMed: 19932385]. [PubMed Central: PMC2806427].

13. Henn A, Flateau C, Gallien S. Primary HIV Infection: Clinical Presentation, Testing, and Treatment. Curr Infect Dis Rep. 2017;19(10):37. doi: 10.1007/s11908-017-0588-3. [PubMed: 28884279].

14. O'Brien SJ, Nelson GW. Human genes that limit AIDS. Nat Genet. 2004;36(6):565-74. doi: 10.1038/ng1369. [PubMed: 15167933].

15. Dean M, Carrington M, Winkler C, Huttley GA, Smith MW, Allikmets R, et al. Genetic restriction of HIV-1 infection and progression to AIDS by a deletion allele of the CKR5 structural gene. Hemophilia Growth and Development Study, Multicenter AIDS Cohort Study, Multicenter Hemophilia Cohort Study, San Francisco City Cohort, ALIVE Study. Science. 1996;273(5283):1856-62. doi: 10.1126/science.273.5283.1856. [PubMed: 8791590].

16. Shin HD, Winkler C, Stephens JC, Bream J, Young H, Goedert JJ, et al. Genetic restriction of HIV-1 infection and AIDS progression by promoter alleles of interleukin 10. Am J Hum Genet. 1999;65(4):A15.

17. Poorolajal J, Hooshmand E, Mahjub H, Esmailnasab N, Jenabi E. Survival rate of AIDS disease and mortality in HIV-infected patients: a meta-analysis. Public Health. 2016;139:3-12. doi: 10.1016/j.puhe.2016.05.004. [PubMed: 27349729].

18. Carrington M, O'Brien SJ. The influence of HLA genotype on AIDS. Annu Rev Med. 2003;54:535-51. doi: 10.1146/annurev.med.54.101601.152346. [PubMed: 12525683].

19. Sousa AE, Carneiro J, Meier-Schellersheim M, Grossman Z, Victorino RM. CD4 T cell depletion is linked directly to immune activation in the pathogenesis of HIV-1 and HIV-2 but only indirectly to the viral load. J Immunol. 2002;169(6):3400-6. doi: 10.4049/jimmunol.169.6.3400. [PubMed: 12218162].

20. Siegel K, Schrimshaw EW, Dean L. Symptom interpretation: implications for delay in HIV testing and care among HIV-infected late middle-aged and older adults. AIDS Care. 1999;11(5):525-35. doi: 10.1080/09540129947686. [PubMed: 10755028]. 